\title{
ON THE INFLUENCE FACTORS OF AUDIO-VISUAL COMFORT OF MOUNTAIN LANDSCAPE BASED ON FIELD SURVEY
}

\author{
Fangfang LIU $1,2^{\star}$, Jian $\mathrm{KANG}^{2,} 1^{\star}$, Qi MENG ${ }^{1,2^{*}}$ \\ ${ }^{1}$ Heilongjiang Cold Region Architectural Science Key Laboratory, School of Architecture, \\ Harbin Institute of Technology, Harbin, PR China \\ ${ }^{2}$ UCL Institute for Environmental Design and Engineering, \\ University College London, London, United Kingdom
}

Received 04 September 2019; accepted 06 January 2020

\section{Highlights}

The audio-visual comfort positively correlated with the percentage of tourists engaged in a dynamic state (walking and running) in mountainous areas.

The audio-visual comfort significantly negatively correlated with density, sound pressure level and sound psychoacoustic parameters including fluctuation and loudness.

- An increase in the critical point of SPL in mountainous areas compared with that in plain urban ones suggesting that respondents' tolerance of natural sounds is high relative to that of traffic noise.

\begin{abstract}
This study is aimed to investigate factors that can affect the audio-visual comfort of tourists with a mountainous landscape. The results reveal that the audio-visual comfort of tourists is positively correlated with the percentage of tourists engaged in a dynamic state. In contrast, the audio-visual comfort has strong negative correlations with density, sound pressure level and sound characters including fluctuation and loudness. Overall, respondents in the mountain area find the audio-visual level most comfortable when the ratio of visitors in dynamic states is greater than $33 \%$, the fluctuation of sound is within 0.08 vacil, the loudness of sound is less than 46 sone, the population density is less than 0.822 person $/ \mathrm{m}^{2}$, and the sound pressure level is less than $82 \mathrm{~dB}$. Compared with urban areas, a $24 \mathrm{~dB}$ increase in the sound pressure level threshold is observed for a positive evaluation of audio-visual comfort in the mountain area.
\end{abstract}

Keywords: visual comfort, acoustic comfort, audio-visual comfort, mountain landscape, noise pollution, soundscape.

\section{Introduction}

Currently, an increasing number of urban people would like to get out of town after work to relieve stress. According to National Park Service Visitor Use Statistics (2016), $48 \%$ more people visited Yellowstone National Park (U.S.) in 2016 than a decade ago, and the surging crowd of visitors along with the decrease in biodiversity give rise to a change of soundscape in natural environments: sounds coming from wildlife are being replaced by anthropogenic noise (Francis et al., 2017). Recent studies have indicated that visitors' attitudes can be correlated with the type of sounds (i.e., natural and human-caused sounds) and the characteristics, activities and behaviours of the crowd of visitors (Haas et al., 1998; Marin et al., 2011; Sever \&
Verbič, 2018). Therefore, in order to improve the quality of visitors' experiences, it is necessary to investigate the factors that can affect audio-visual comfort, which include the natural landscape, soundscape, and human behaviour.

Previously, the relationship between subjective comfort assessment and the sound environment was investigated with the emergence of the "soundscape" concept (Brown et al., 2011; Hao et al., 2015; Joynt \& Kang, 2010; Kang, 2007; Yang \& Kang, 2005; Yu \& Kang, 2009; Zhang \& Kang, 2007). The results revealed that a better acoustic comfort assessment was not always related to a low noise level, and physiological changes in the human body can be associated with characteristics of soundscapes, such as the type of sounds and sound pressure levels (De Ruiter, 2005; Kang, 2007). For example, participants who experienced

*Corresponding author. E-mails: liufangfang@hit.edu.cn; j.kang@ucl.ac.uk; mengq@hit.edu.cn 
a 90-minute walk in a natural environment showed reduced risk of suffering from mental illness than those who took the same amount of exercise in an urban area (Francis et al., 2017). Moreover, in contrast with traffic noise in urban areas that incurs stress and impedes the recovery process, natural sounds such as singing birds, gentle wind and ocean waves were beneficial for patients' recovery from stress and the restoration of their attention (Bratman et al., 2012). In addition, research has demonstrated that natural sounds can enhance the perception of natural environments and improve subjective comfort (Francis et al., 2017; Marin et al., 2011; Newman et al., 2012; Pilcher et al., 2008; Watson et al., 2014). For natural organisms, sound pressure levels (SPLs) were positively correlated with the characteristics of the substratum while acoustic complexity was positively correlated with fish diversity in protected marine areas (Bertucci et al., 2016). Similarly, the richness of bird species can be affected by acoustic entropy, acoustic evenness and the normalized difference in the soundscape index. Consequently, soundscape assessment can be used to monitor ecological conditions (Fuller et al., 2015).

As for visual quality, it was revealed that both vegetation and bodies of water can fundamentally contribute to a positive evaluation of landscape scenes, while human activities reduce the scenic beauty in industrial or mining areas (Arriaza et al., 2004; Barroso et al., 2012; Bulut \& Yilmaz, 2008; López-Martínez, 2017). Moreover, visual quality can be influenced by factors including the water surface area, the widths of pedestrian walkways, the functioning of recreational areas, the plant composition, the plant colour composition, and the plant species diversity (Polat \& Akay, 2015). For example, Dupont et al. demonstrated that salient infrastructural constructions can draw human's visual attention while non-salient objects provided an optimal visual integration into a landscape (Dupont et al., 2016, 2017). Arriaza et al. developed a methodology for assessing the visual quality of agricultural landscapes through the combination of direct and indirect techniques of landscape valuation (Arriaza et al., 2004).

In addition to sound or visual evaluation alone, the audio-visual environment as a total environment has been investigated for subjective perceptions. For example, Hong and Jeon demonstrated that audio-visual interactions had an effect on physiology and psychology in the human body, giving rise to feelings of either happiness or distress. As such, the environmental quality depends on factors beyond soundscape (Hong \& Jeon, 2013, 2014). Preliminary work in neuroscience also revealed that the complicated audio-visual interactions provide insight into determining perceptions (Schormans et al., 2017; Watkins et al., 2007). Furthermore, Preis et al. investigated interactions among feeling, hearing, and vision (Preis et al., 2015). In fact, total environmental consciousness involves a combination of all types of senses, and a reasonable assessment of an environment should consider all factors that can affect these perceptions. Recently, subjective comfort in the outdoor urban area has been linked with acoustic, lighting and thermal factors (Liu \& Kang, 2018; Rossi et al., 2015).

The improvement of audio-visual comfort in urban areas has been intensively investigated in previous studies (Liu \& Kang, 2018); however, few efforts focus on audio-visual comfort in mountainous areas. Due to their special mountainous topography, large green areas, and variety of biotic and abiotic natural sounds, mountain areas are becoming a good choice for relaxation. In comparison with plain urban areas, both the sounds and the visual environment of mountainous areas are quite different. For example, the terrain fluctuation effect is more prominent, which affects the spatial distribution of soil, vegetation and animals, giving rise to the landscape's spatial heterogeneity and its spatial-temporal dynamics (Hong \& Jeon, 2014). In addition, the street canyon effect is enhanced in mountain areas (Hong \& Jeon, 2014; Kang, 2000), leading to a more complex and significant acoustic impact (Xie et al., 2016; Yan et al., 2013). Furthermore, SPL can be increased up to $30 \mathrm{~dB}$ in the Valley-slope configuration in comparison with a flat ground situation (Renterghem et al., 2007).

The aim of this study is therefore to investigate factors that can influence audio-visual comfort as part of the environment as a whole in mountainous areas in order to improve the quality of visitors' experiences. Based on the field survey method, relationships between certain factors (elevation, population density, human behavioural patterns, sound parameters, and sound source) and subjective attitudes towards each scenic site are analysed. In addition, the dynamic balance between tourists and nature in the mountainous area is discussed.

\section{Method}

\subsection{Field study}

This research was based on the field survey of ten major scenic sites in Huangshan Nature Park, a protected area located in Anhui province, China $\left(30.08^{\circ} \mathrm{N}, 118.09^{\circ} \mathrm{E}\right)$, as shown in Figure 1.

The park has a typical mountain landscape with a stable-balanced ecosystem. The plant community is vertically

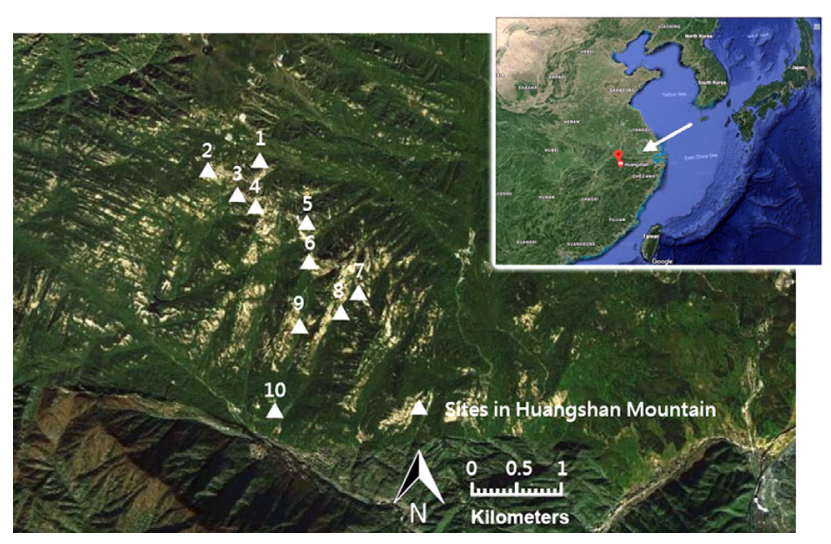

Figure 1. Map of the scenic sites chosen for the study 


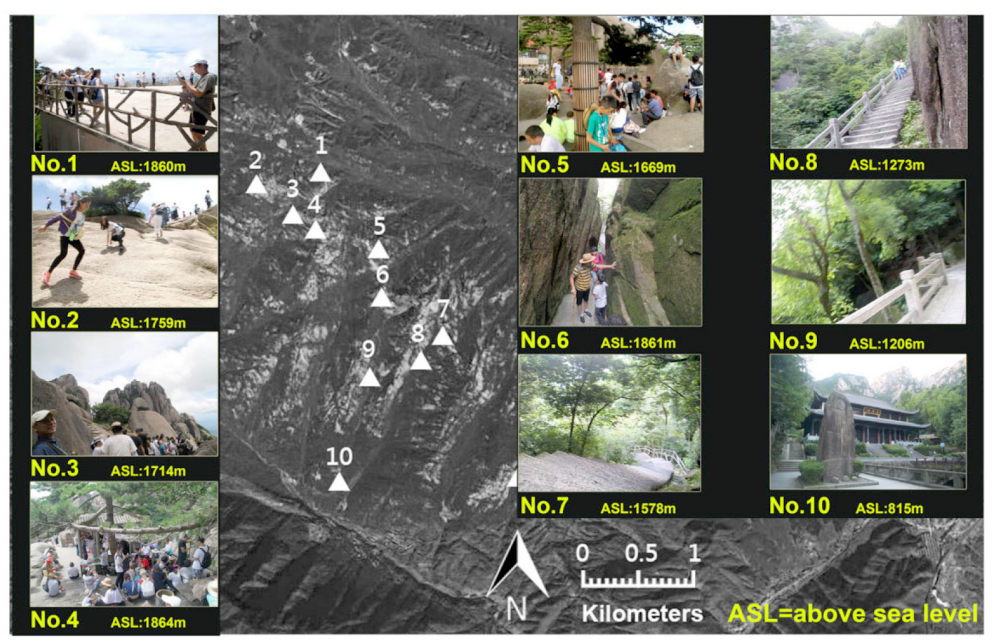

Figure 2. The scenic sites chosen for the study

distributed with a vegetation coverage rate of $93.0 \%$ and a forest coverage rate of $84.7 \%$. Moreover, the park has a variety of wild animals, including 176 kinds of birds, 48 kinds of reptiles, and 24 kinds of fish, all of which can be natural acoustic sources (UNESCO, 2019). The local image and elevation (ASL) for each site are shown in Figure 2 .

\subsection{Measurement of audio-visual environment}

The acoustic signals were collected over dual channels using an acoustic signal data collector (ZODIAC/ DIC10). The acoustic signals were recorded at a height of $1.5 \mathrm{~m}$ above the ground to obtain high-fidelity stereo recordings (Kang, 2007; Liu \& Kang, 2018). The highdefinition (HD) video signals were recorded using a CANON EOS 500D camera. The altitude of each scenic site was measured with a Trueyard SP2000H laser range finder. The temperature range for recording was from 20 to $25^{\circ} \mathrm{C}$, relative humidity range was from 38 to $55 \%$, and atmospheric pressure range was from $65 \mathrm{kPa}$ to $108 \mathrm{kPa}$. Subsequently, the acoustic signals were treated using Artemis Analyzer, through which SPL (dB), frequency $(\mathrm{Hz})$, and psychoacoustic variables including sharpness (acum), fluctuation (vacil), loudness (sone), and roughness (asper) were derived. Except for loudness, the average values were calculated for each sound characteristic. The assessment of loudness was based on the $N_{5}$ value rather than the average one since that was more suitable for evaluating time varying sounds (Fastl \& Zwicker, 2007). The population density (person $/ \mathrm{m}^{2}$ ), the statistics of human behaviour, including the dynamic/static state (walking, running, sitting, standing) and the sound source (talking, playing, footsteps, eating or drinking) were obtained from the video samples. The percentage of sound from each type of activity was calculated by dividing the number of people performing a certain activity by the total population number.

\subsection{Audio-visual comfort survey}

Participants were selected according to Motoyama (Motoyama \& Hanyu, 2014). In particular, tourists aging from 18 to 37 years old, who exhibited normal hearing and regular or corrected-to-normal vision, were selected as the study subjects. A sample size of $20 \sim 25$ has been widely used in subjective comfort assessments (Hermida Cadena et al., 2017; Ratcliffe et al., 2013; Ren \& Kang, 2015). Consequently, a sample size of 23 was adopted in this study, with a male-to-female ratio of $\sim 1: 1$ (male 11 , female 12) to ensure that the sample sex ratio was balanced. Participants were asked to experience the environment as pedestrians on ten scenic sites (Figure 2).

The questionnaire survey method has been widely used to investigate subjective attitudes towards an urban environment (Kang, 2007; Liu \& Kang, 2018; Preis et al., 2015; Zhang \& Kang, 2007). In this study, the parameters of visual comfort, acoustic comfort, and audio-visual comfort were measured using a Likert scale, in accordance with previous studies (Bratman et al., 2012; Yu \& Kang, 2009). Specifically, each parameter was graded as per the following linear scale: 1-very uncomfortable, 2 -uncomfortable, 3-neither comfortable nor uncomfortable, 4-comfortable, and 5-very comfortable. The questionnaire was completed by participants at each scenic site in 20-30 minutes during the field survey. At the beginning of the test, each participant was asked to fill in a questionnaire regarding their age, gender, and education. For every site, participants were asked to indicate their agreement by means of a 5-point Likert scale, which ranges from "very uncomfortable" to "very comfortable". When answering questions related to acoustic comfort in the questionnaire, the participants were asked to close their eyes. When answering the questions related to visual comfort, they covered their ears. When answering audio-visual questions, the entire environment was open to them. 


\subsection{Audio-visual comfort survey}

After calculating the data from the questionnaires, the reliability coefficient was estimated as 0.875 (Cronbach's alpha). The reliability coefficient was within the range of $0.9>\alpha \geq 0.8$, indicating that the questionnaire satisfied the reliability requirement (George \& Mallery, 2013). Multivariate analysis of variance (MANOVA) was used to evaluate the effect of statistically significant mean differences within the parameters of visual, acoustic, and audio-visual in terms of each possible influencing factor. The Spearman's correlation coefficients $r$ and $p$ were used to find correlations between factors and perceptual parameters, while the quadratic regression was used to further analyse their relationships (Liu \& Kang, 2018; Yu et al., 2017). It should be noted that regression results indicate that coefficients of determination $R^{2}$ from quadratic regression are closer to 1 than those from linear regression. As a result, quadratic regression was adapted in this study. Moreover, regression curves using mean values of subjective assessment demonstrate similar trends to their corresponding ones based on all subjective data, and significant $p$ values are less than 0.01 in all analyses.

\subsection{Landscape and acoustic data for each site}

Landscape characteristics and data related to auditory stimuli (loudness, sharpness, fluctuation, and roughness) for each scenic site are shown in Table 1. Figure 3 compares A-weighted SPL among the ten scenic sites collected over time. It can be seen that A-weighted SPL is distributed from the lowest value of $52.53 \mathrm{~dB}$ (Site No. 7) to the highest one of $85.53 \mathrm{~dB}$ (Site No. 10).

The distribution of psychoacoustic variables is shown in Table 1. As seen in Table 1, the highest sharpness and loudness are shown on Site No. 10, which is associated with the strong annoying noise from the cicadas at a low altitude (ASL: $815 \mathrm{~m}$ ). Conversely, the lowest sharpness appears on Site No. 3, a scene site located at the mountain peak, where the diversity and quantity of wildlife are reduced due to the low temperatures at this high altitude (ASL: 1714 m, Figure 2).

\section{Results}

The improvement of audio-visual comfort in urban areas has been extensively investigated; however, few efforts are focusing on audio-visual comfort around tourist attractions involving mountainous landscapes. Mean acoustic,

Table 1. Landscape and acoustic characteristics for the investigated samples

\begin{tabular}{|c|c|c|c|c|c|c|c|}
\hline $\begin{array}{c}\text { Site } \\
\text { No. }\end{array}$ & $\begin{array}{c}\text { Elevation } \\
(\mathrm{m})\end{array}$ & $\begin{array}{c}\text { Density } \\
(\text { person/m }\end{array}$ & $\begin{array}{c}\text { SPL } \\
(\mathrm{dB})\end{array}$ & $\begin{array}{c}\text { Loudness } \\
(\text { sone })\end{array}$ & $\begin{array}{c}\text { Sharpness } \\
(\text { acum })\end{array}$ & $\begin{array}{c}\text { Fluctuation } \\
(\text { vacil) }\end{array}$ & $\begin{array}{c}\text { Roughness } \\
(\text { asper})\end{array}$ \\
\hline 1 & 1860.00 & 0.20 & 71.30 & 23.26 & 3.06 & 0.04 & 2.94 \\
\hline 2 & 1759.00 & 0.35 & 77.30 & 28.06 & 2.84 & 0.07 & 3.05 \\
\hline 3 & 1714.00 & 3.00 & 78.61 & 27.17 & 2.12 & 0.19 & 4.59 \\
\hline 4 & 1864.00 & 2.50 & 79.81 & 39.32 & 3.37 & 0.08 & 3.15 \\
\hline 5 & 1669.00 & 1.80 & 80.91 & 41.03 & 3.16 & 0.08 & 3.44 \\
\hline 6 & 1861.00 & 0.07 & 66.05 & 14.79 & 3.13 & 0.05 & 3.61 \\
\hline 7 & 1578.00 & 0.05 & 62.33 & 13.48 & 3.45 & 0.02 & 1.87 \\
\hline 8 & 1273.00 & 0.03 & 78.06 & 38.45 & 5.58 & 0.05 & 2.90 \\
\hline 9 & 1206.00 & 0.04 & 77.16 & 35.75 & 5.06 & 0.02 & 3.10 \\
\hline 10 & 815.00 & 0.05 & 84.13 & 48.41 & 6.59 & 0.03 & 2.80 \\
\hline
\end{tabular}

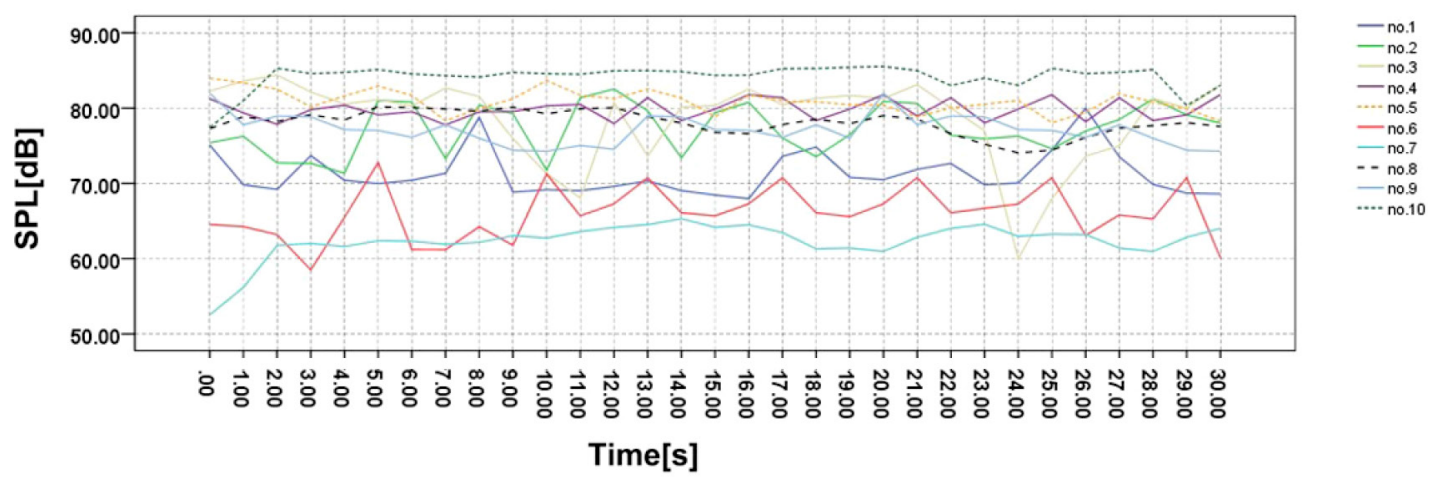

Figure 3. The sound pressure level (SPL) recorded at the selected sites 


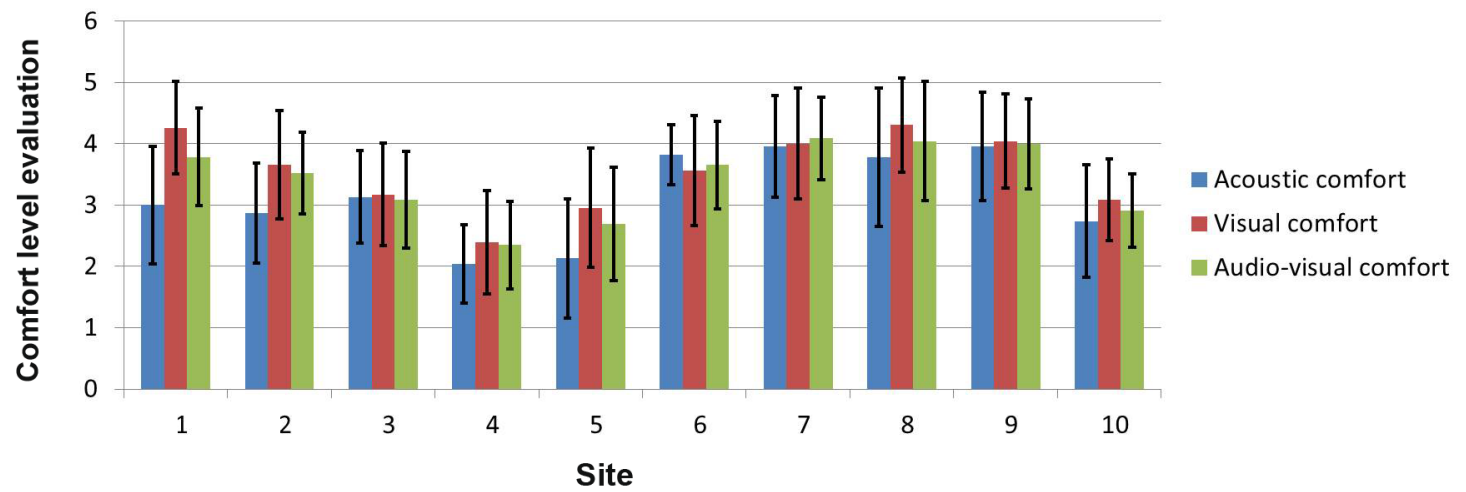

Figure 4. Mean acoustic, visual, and audio-visual comfort levels along with standard deviations at the selected scenic sites. The comfort level is graded as per the following linear scale: 1 - very uncomfortable; 2 - uncomfortable; 3 - neither comfortable nor uncomfortable; 4 - comfortable; and 5 - very comfortable

visual, and audio-visual comfort levels are compared in Figure 4 along with standard deviations. The highest and lowest values are presented at Sites No. 7 and No. 4, respectively.

\subsection{Multivariate analysis of variance (MANOVA)}

MANOVA results indicate that significant mean differences are observed in visual, acoustic, and audio-visual comfort depending on elevation, population density, dynamic (walking or running) or static (sitting or standing) states of human behaviour, and anthropogenic sounds (talking, playing, eating or drinking, and other behaviours) $(p<0.001$ for all, Table 2). Moreover, for both acoustic and audio-visual comfort, significant mean differences are also observed in terms of SPL, and psychoacoustic parameters including sharpness, fluctuation, loudness, and roughness $(p<0.001$ for all, Table 2$)$.

The various relationships among the variables in question were analysed under the following classifications:

Table 2. MANOVA results for influence factors and subjective comfort assessment. SS = Type III sum of squares; df = degrees of freedom; MS = Mean Square; $F=$ F ratio; Sig. = significance; $\eta_{p}{ }^{2}=$ partial eta squared (effect size). Significance (at 0.05$)$ is in bold

\begin{tabular}{|c|c|c|c|c|c|c|}
\hline Source & SS & $\mathrm{df}$ & MS & $F$ & Sig. & $\eta_{p}^{2}$ \\
\hline \multicolumn{7}{|l|}{ Elevation $(\mathrm{M})$} \\
\hline Visual comfort & 82.370 & 9 & 9.152 & 13.186 & 0.000 & 0.350 \\
\hline Acoustic comfort & 107.917 & 9 & 11.991 & 16.452 & 0.000 & 0.402 \\
\hline Audio-visual comfort & 78.370 & 9 & 8.708 & 14.805 & 0.000 & 0.377 \\
\hline \multicolumn{7}{|l|}{ Density (person/m²) } \\
\hline Visual comfort & 72.783 & 8 & 9.098 & 12.390 & 0.000 & 0.310 \\
\hline Acoustic comfort & 90.874 & 8 & 11.359 & 14.152 & 0.000 & 0.339 \\
\hline Audio-visual comfort & 62.522 & 8 & 7.815 & 11.892 & 0.000 & 0.301 \\
\hline \multicolumn{7}{|l|}{ Dynamic state (\%) } \\
\hline Visual comfort & 79.739 & 8 & 9.967 & 14.182 & 0.000 & 0.339 \\
\hline Acoustic comfort & 107.722 & 8 & 13.465 & 18.536 & 0.000 & 0.402 \\
\hline Audio-visual comfort & 76.978 & 8 & 9.622 & 16.260 & 0.000 & 0.371 \\
\hline \multicolumn{7}{|l|}{ Static state $(\%)$} \\
\hline Visual comfort & 79.739 & 8 & 9.967 & 14.182 & 0.000 & 0.339 \\
\hline Acoustic comfort & 107.722 & 8 & 13.465 & 18.536 & 0.000 & 0.402 \\
\hline Audio-visual comfort & 76.978 & 8 & 9.622 & 16.260 & 0.000 & 0.371 \\
\hline \multicolumn{7}{|l|}{ Walking (\%) } \\
\hline Visual comfort & 78.696 & 8 & 9.837 & 13.903 & 0.000 & 0.335 \\
\hline Acoustic comfort & 107.830 & 8 & 13.479 & 18.567 & 0.000 & 0.402 \\
\hline Audio-visual comfort & 76.978 & 8 & 9.622 & 16.260 & 0.000 & 0.371 \\
\hline
\end{tabular}


End of Table 2

\begin{tabular}{|c|c|c|c|c|c|c|}
\hline Source & SS & $\mathrm{df}$ & MS & $F$ & Sig. & $\eta_{p}{ }^{2}$ \\
\hline \multicolumn{7}{|l|}{ Running (\%) } \\
\hline Visual comfort & 57.304 & 5 & 11.461 & 14.442 & 0.000 & 0.244 \\
\hline Acoustic comfort & 79.613 & 5 & 15.923 & 18.906 & 0.000 & 0.297 \\
\hline Audio-visual comfort & 59.696 & 5 & 11.939 & 18.062 & 0.000 & 0.287 \\
\hline \multicolumn{7}{|l|}{ Sitting (\%) } \\
\hline Visual comfort & 81.587 & 8 & 10.198 & 14.685 & 0.000 & 0.347 \\
\hline Acoustic comfort & 107.570 & 8 & 13.446 & 18.492 & 0.000 & 0.401 \\
\hline Audio-visual comfort & 78.348 & 8 & 9.793 & 16.724 & 0.000 & 0.377 \\
\hline \multicolumn{7}{|l|}{ Standing (\%) } \\
\hline Visual comfort & 66.500 & 7 & 9.500 & 12.511 & 0.000 & 0.283 \\
\hline Acoustic comfort & 90.852 & 7 & 12.979 & 16.241 & 0.000 & 0.339 \\
\hline Audio-visual comfort & 60.761 & 7 & 8.680 & 13.109 & 0.000 & 0.292 \\
\hline \multicolumn{7}{|l|}{ Talking (\%) } \\
\hline Visual comfort & 82.370 & 9 & 9.152 & 13.186 & 0.000 & 0.350 \\
\hline Acoustic comfort & 107.917 & 9 & 11.991 & 16.452 & 0.000 & 0.402 \\
\hline Audio-visual comfort & 78.370 & 9 & 8.708 & 14.805 & 0.000 & 0.377 \\
\hline \multicolumn{7}{|l|}{$\begin{array}{l}\text { Playing without talking } \\
\text { (\%) }\end{array}$} \\
\hline Visual comfort & 78.696 & 8 & 9.837 & 13.903 & 0.000 & 0.335 \\
\hline Acoustic comfort & 107.830 & 8 & 13.479 & 18.567 & 0.000 & 0.402 \\
\hline Audio-visual comfort & 76.978 & 8 & 9.622 & 16.260 & 0.000 & 0.371 \\
\hline \multicolumn{7}{|l|}{ Eating or Drinking (\%) } \\
\hline Visual comfort & 81.500 & 7 & 11.643 & 16.831 & 0.000 & 0.347 \\
\hline Acoustic comfort & 105.809 & 7 & 15.116 & 20.656 & 0.000 & 0.394 \\
\hline Audio-visual comfort & 78.000 & 7 & 11.143 & 19.064 & 0.000 & 0.375 \\
\hline \multicolumn{7}{|l|}{ Other behaviour (\%) } \\
\hline Visual comfort & 72.783 & 8 & 9.098 & 12.390 & 0.000 & 0.310 \\
\hline Acoustic comfort & 90.874 & 8 & 11.359 & 14.152 & 0.000 & 0.339 \\
\hline Audio-visual comfort & 62.522 & 8 & 7.815 & 11.892 & 0.000 & 0.301 \\
\hline \multicolumn{7}{|l|}{ SPL $(\mathrm{dB})$} \\
\hline Acoustic comfort & 107.917 & 9 & 11.991 & 16.452 & 0.000 & 0.402 \\
\hline Audio-visual comfort & 78.370 & 9 & 8.708 & 14.805 & 0.000 & 0.377 \\
\hline \multicolumn{7}{|l|}{ Sharpness (acum) } \\
\hline Acoustic comfort & 107.917 & 9 & 11.991 & 16.452 & 0.000 & 0.402 \\
\hline Audio-visual comfort & 78.370 & 9 & 8.708 & 14.805 & 0.000 & 0.377 \\
\hline \multicolumn{7}{|l|}{ Fluctuation (vacil) } \\
\hline Acoustic comfort & 107.917 & 9 & 11.991 & 16.452 & 0.000 & 0.402 \\
\hline Audio-visual comfort & 78.370 & 9 & 8.708 & 14.805 & 0.000 & 0.377 \\
\hline \multicolumn{7}{|l|}{ Loudness (sone) } \\
\hline Acoustic comfort & 107.917 & 9 & 11.991 & 16.452 & 0.000 & 0.402 \\
\hline Audio-visual comfort & 78.370 & 9 & 8.708 & 14.805 & 0.000 & 0.377 \\
\hline \multicolumn{7}{|l|}{ Roughness (asper) } \\
\hline Acoustic comfort & 107.917 & 9 & 11.991 & 16.452 & 0.000 & 0.402 \\
\hline Audio-visual comfort & 78.370 & 9 & 8.708 & 14.805 & 0.000 & 0.377 \\
\hline
\end{tabular}


1) effect of elevation, 2) effect of visitor density (person/ $\mathrm{m}^{2}$ ), 3) effect of human behaviour patterns, 4) effect of sound parameters: SPL and sound characteristics (sharpness, fluctuation, loudness, and roughness), and 5) effect of sound sources.

\subsection{Effect of elevation}

Table 3 contains the Spearman's correlation coefficient between related variables and subjective comfort levels, including the two-tailed significance levels. It can be seen that there is no significant correlation between elevation and visual comfort $(r=-0.273, p>0.05)$. This is also observed in the evaluation of both acoustic comfort $(r=-0.310, p>0.05)$ and audio-visual comfort assessment $(r=0.333, p>0.05)$. Since the Spearman's correlation coefficient $p$ is greater than 0.05 , elevation is not a major factor in determining subjective comfort. Figure 5a shows the relationships between elevation and the comfort evaluation with the corresponding quadratic regressions and correlation coefficients $R^{2}$. In Figure 5a, each symbol represents the average of the subjective evaluation of the visual, acoustic, and audio-visual comfort for a scene site with a specific value of elevation. $R^{2}$ values of $0.228,0.261$, and 0.274 are observed for visual, acoustic, and audio-visual comfort, thereby indicating that the elevation variation accounts for $22.8 \%, 26.1 \%$, and $27.4 \%$ of the variability in the visual, acoustic and audio-visual comfort levels, respectively. In Figure 5a, the shapes of the three curves are similar, and the highest audio-visual comfort is observed at $1.300 \mathrm{~m}$ ASL.

In addition to audio-visual comfort, the correlations between elevation and SPL as well as sound characteristics were investigated. From the data shown in Table 4, it can be seen that the influence of elevation is not significant on SPL $(r=-0.224, p>0.05)$, fluctuation $(r=0.588, p>0.05)$, loudness $(r=-0.358$, $p>0.05)$, or roughness $(r=0.515, p>0.05)$; however, a significant negative correlation is observed between elevation and sharpness, as can be inferred from Table 4 $\left(r=-0.685^{*}, p<0.05\right)$. One possible explanation is that sharp sounds from birds and insects in warm zones at the base of a mountain are alleviated with the increase in elevation, which leads to a decrease in temperature $\left(\sim 12{ }^{\circ} \mathrm{C}\right)$ and reduced prevalence of wildlife. However, sounds from the wind are stronger at the summits of mountains, which can compensate for the alleviation of sharp sounds from birds and insects. Moreover, anthropogenic sounds, which are dependent on road conditions (e.g., width, inclination, and geographical feature), contribute to the overall soundscape (Liu \& Kang, 2018; Xie et al., 2016). As such, the correlation between elevation and loudness is not significant.
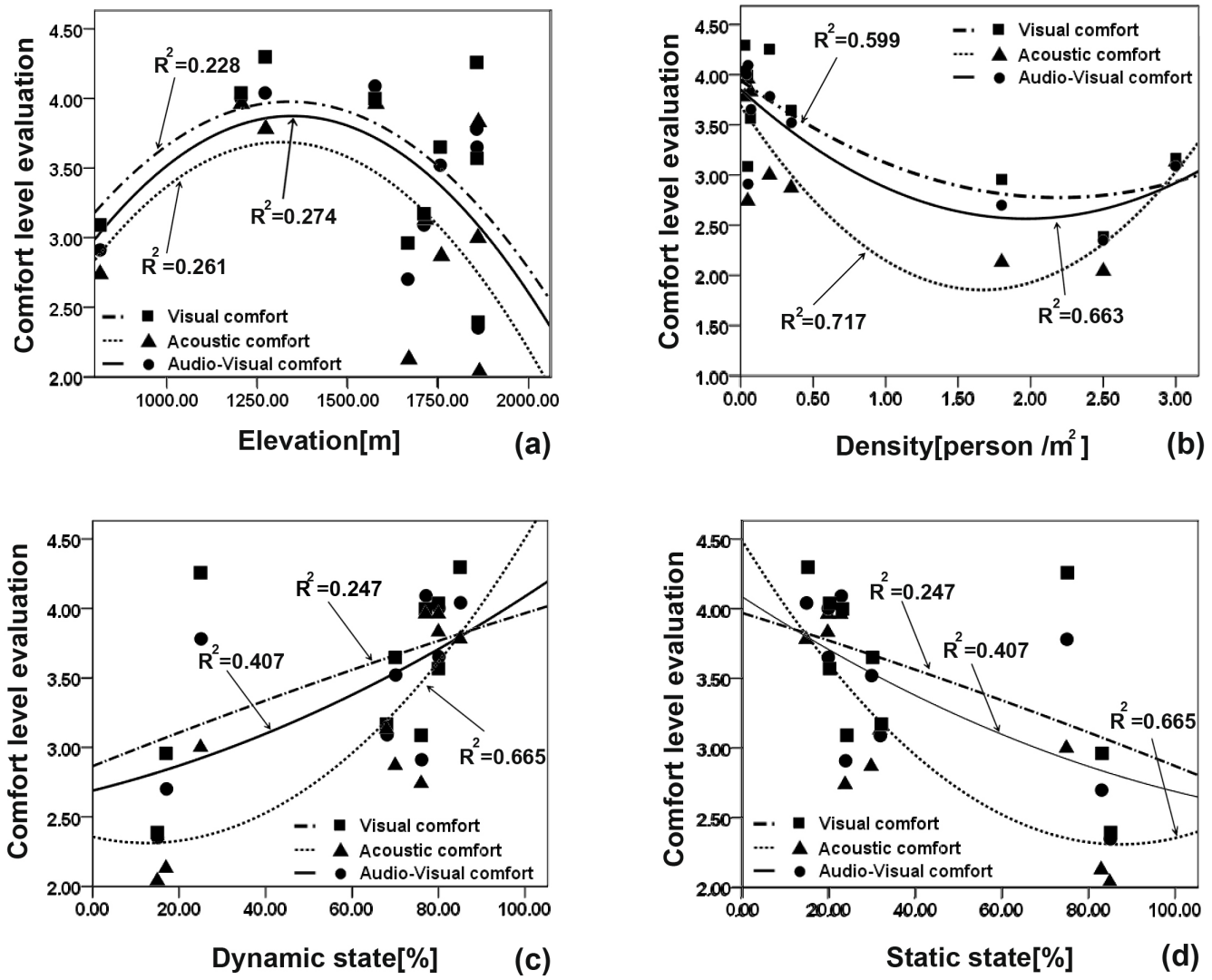

Figure 5. The relationship between comfort evaluation and elevation and human behaviour: (a) elevation; (b) density; (c) the ratio of dynamic states, and (d) the ratio of static states. The comfort level is graded as per the following linear scale: 1 - very uncomfortable; 2 - uncomfortable; 3 - neither comfortable nor uncomfortable; 4 - comfortable and 5 - very comfortable 


\subsection{Effect of visitor density (person/ $/ \mathrm{m}^{2}$ )}

Both visual and audio-visual comfort are negatively correlated with population density, and their corresponding Spearman's correlation coefficients are listed in Table 3 $\left(r=-0.675^{*}, p<0.05\right.$ for visual comfort; and $r=-0.729^{*}$, $p<0.05$ for audio-visual comfort). Figure $5 \mathrm{~b}$ depicts the relationships between population density and the comfort level evaluation with the corresponding quadratic regressions and correlation coefficients $R^{2}$. In this work, a comfort level of 3 forms the critical point between positive and negative participant attitudes. When population density is smaller than 0.82 person $/ \mathrm{m}^{2}$, participants' preferred audio-visual comfort levels are reached. It should be noted that this critical value is slightly high relative to the one for urban open spaces, where a population density $<0.78$ person $/ \mathrm{m}^{2}$ is required to reach high comfort (Meng et al., 2017). This result indicates that tourists have an increased tolerance to the crowd density, possibly due to the safety consideration in the unfamiliar mountainous areas.

Table 3. Spearman's correlation coefficient between related variables and subjective comfort levels, including the two-tailed significance levels. Significant correlations are marked with ${ }^{\star}(p<0.05)$ and ${ }^{\star *}(p<0.01)$

\begin{tabular}{|l|c|c|c|}
\hline \multicolumn{1}{|c|}{ Factor } & $\begin{array}{c}\text { Visual } \\
\text { comfort } \\
\text { evaluation }\end{array}$ & $\begin{array}{c}\text { Acoustic } \\
\text { comfort } \\
\text { evaluation }\end{array}$ & $\begin{array}{c}\text { Audio-visual } \\
\text { comfort } \\
\text { evaluation }\end{array}$ \\
\hline Elevation & -0.273 & -0.310 & 0.333 \\
\hline Density & $-0.675^{\star}$ & -0.607 & $-0.729^{\star}$ \\
\hline $\begin{array}{l}\text { Ratio of dynamic } \\
\text { states }\end{array}$ & $0.644^{*}$ & $0.790^{\star *}$ & $0.748^{\star}$ \\
\hline Ratio of static states & $-0.644^{\star}$ & $-0.790^{\star *}$ & $-0.748^{\star}$ \\
\hline Ratio of walking & 0.547 & $0.720^{\star}$ & $0.632^{\star}$ \\
\hline Ratio of running & 0.497 & 0.234 & 0.515 \\
\hline Ratio of sitting & $-0.675^{\star}$ & -0.582 & -0.535 \\
\hline Ratio of standing & -0.293 & -0.535 & -0.482 \\
\hline SPL & - & $-0.778^{* *}$ & $-0.782^{\star *}$ \\
\hline Sharpness & - & 0.122 & 0.212 \\
\hline Fluctuation & - & -0.596 & $-0.709^{*}$ \\
\hline Loudness & - & $-0.681^{\star}$ & $-0.624^{\star}$ \\
\hline Roughness & - & -0.170 & -0.503 \\
\hline
\end{tabular}

In Figure 5b, $R^{2}$ values of $0.599,0.717$, and 0.663 can be observed for visual, acoustic, and audio-visual comfort, respectively, indicating that the elevation variation accounts for $59.9 \%, 71.7 \%$, and $66.3 \%$ of the variability in the visual, acoustic and audio-visual comfort levels, respectively. Therefore, audio-visual comfort can be improved by controlling the population density at the scenic site.

It is noted that the parabolic shape of the three regression curves is mainly caused by the scenic site with population density of three persons $/ \mathrm{m}^{2}$. The audiovisual comfort level is 3.2 , indicating a positive attitude from respondents on this site. As shown in Figure 2, the corresponding site is located at the mountain peak, exhibiting dangerous terrain and a stony physiognomy. The unexpected high level of subjective comfort suggests that an individual's attention is prone to being attracted by some special landscape even it shows high population density.

In addition, the relationship between population density and psychoacoustic variables are investigated. Table 4 indicates that a significant negative correlation exists between density and sharpness (acum) $\left(r=-0.754^{*}, p<\right.$ 0.05 ), while positive correlations are observed between density and fluctuation $\left(r=0.833^{* *}, p<0.01\right)$, and between roughness and density $\left(r=0.657^{\star}, p<0.05\right)$. These results demonstrate that visitor activity can affect the soundscape in a mountainous area. However, loudness is not significantly correlated with density, as can be inferred from Table $4(p>0.05)$.

Table 4. Spearman's correlation coefficient between related variables and sound parameters, including the two-tailed significance levels. Significant correlations are marked with ${ }^{\star}(p<0.05)$ and ${ }^{\star *}(p<0.01)$

\begin{tabular}{|l|c|c|}
\hline \multicolumn{1}{|c|}{ Relevant factors } & Elevation & Density \\
\hline SPL (dB) & -0.224 & 0.328 \\
\hline Sharpness (acum) & $-0.685^{\star}$ & $-0.754^{\star}$ \\
\hline Fluctuation (vacil) & 0.588 & $0.833^{\star *}$ \\
\hline Loudness (sone) & -0.358 & 0.024 \\
\hline Roughness (asper) & 0.515 & $0.657^{\star}$ \\
\hline
\end{tabular}

\subsection{Effect of human behaviour patterns}

One major difference in terms of the soundscape in an urban area versus that of a mountainous area is that there is little noise from cars or other motor vehicles in the latter. That is, the soundscape of a mountainous area is composed of nearly all natural and human-caused sounds. Therefore, it is important to investigate the effect of human behaviour on subjective comfort. On the basis of behaviour patterns, human activity can be categorized into dynamic and static states. The former includes walking and running while the latter includes sitting and standing. A detailed account of human behaviour patterns at each site is shown in Figure 6. The highest ratio of visitors in dynamic states is shown at Site No. $8(85 \%)$, while the lowest is at Site No. 4 (15\%).

Table 3 indicates that a significant positive correlation exists between the ratio of dynamic state and visual comfort $\left(r=0.644^{*}, p<0.05\right)$, between the ratio of dynamic states and acoustic comfort $\left(r=0.790^{* *}, p<0.01\right)$, and between the ratio of dynamic states and audio-visual comfort $\left(r=0.748^{*}, p<0.05\right)$. Figure $5 c$ depicts the relationships between the ratio of dynamic states and the comfort level evaluation with the corresponding quadratic regressions and correlation coefficients $R^{2}$. In Figure 5 c, all three indicators exhibit an increasing trend. In addition, the $R^{2}$ values between the ratio of dynamic states and the visual, acoustic, and audio-visual comfort levels are $0.247,0.665$, and 0.407 , respectively. To encourage positive attitudes, in 


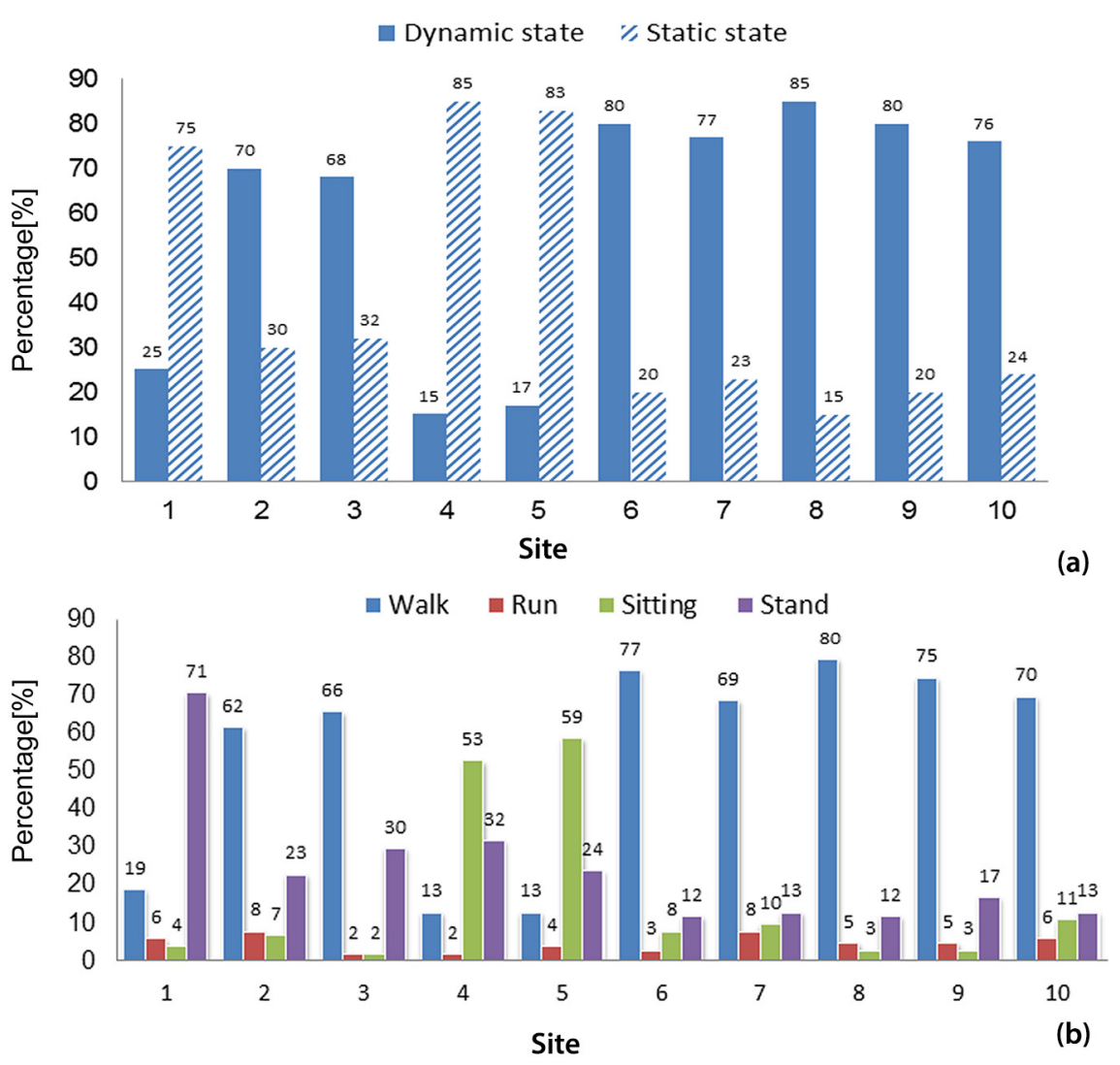

Figure 6. The distribution of human behaviour at each site

terms of audio-visual comfort, from participants, the ratio of dynamic states should be greater than $33 \%$. Figure $5 \mathrm{~d}$ depicts the relationships between the ratio of dynamic states and the comfort level evaluation, displaying opposite trends to those seen in Figure $5 \mathrm{c}$.

The effect of each pattern of human behaviour on subjective comfort was further analysed. From Table 3, positive correlations are observed between the ratio of walking as a human behaviour and acoustic comfort $\left(r=0.720^{*}\right.$, $p<0.05)$ and between the ratio of walking and audiovisual comfort $\left(r=0.632^{*}, p=0.05\right)$. However, there is no significant correlation between the ratio of walking and visual comfort $(r=0.547, p>0.05)$. In addition, coefficients of determination $R^{2}$ based on quadratic regression are $0.216,0.665$, and 0.371 , indicating that the variation in the ratio of walking accounts for $21.6 \%, 66.5 \%$, and $37.1 \%$ for visual, acoustic, and audio-visual comfort levels, respectively (Figure 7a).

In terms of running, the Spearman's correlation coefficient $p$ is greater than 0.05 for the three indicators (the visual, acoustic, and audio-visual comfort levels), as can be inferred from Table 3, suggesting that no significant correlation exists between the ratio of running and subjective comfort. Figure $7 \mathrm{~b}$ shows the relationships between the ratio of running as a human behaviour and the comfort evaluation with the corresponding quadratic regressions and correlation coefficients $R^{2}$. From Figure $7 \mathrm{~b}, R^{2}$ values of $0.452,0.101$, and 0.345 are observed for visual, acoustic, and audio-visual comfort, respectively, indicating that the variation of the ratio of running accounts for $45.2 \%, 10.1 \%$, and $34.5 \%$ of the variability in the visual, acoustic and audio-visual comfort levels, respectively.

From Table 3, it can be seen that there is a significant negative correlation between the ratio of sitting and the visual comfort $\left(r=-0.675^{\star}, p<0.05\right)$. However, no significant correlation can be observed between the ratio of sitting and acoustic comfort $(r=-0.582, p>0.05)$, and between the ratio of sitting and audio-visual comfort $(r=-0.535, p>0.05)$. The coefficients of determination $R^{2}$ based on quadratic regression are $0.588,0.596$, and 0.591 , indicating that the variation of the ratio of sitting accounts for $58.8 \%, 59.6 \%$, and $59.1 \%$ for visual, acoustic, and audio-visual comfort levels, respectively (Figure 7c).

Similar to running, the ratio of standing was not significantly correlated with the three indicators (the visual, acoustic, and audio-visual comfort levels), as can be inferred from Table 3 ( $p>0.05)$. The three regression curves show parabolic shapes, with $R^{2}$ values of $0.543,0.499$, and 0.491 , indicating that the variation of the ratio of sitting accounts for $54.3 \%, 49.9 \%$, and $49.1 \%$ for visual, acoustic, and audio-visual comfort levels, respectively (Figure $7 \mathrm{~d}$ ).

\subsection{Effect of acoustic and psychoacoustic parameters}

Since the subjects had their ears covered when answering questions related to visual comfort in the survey, the 


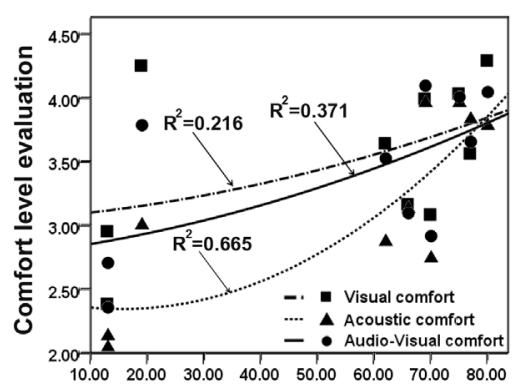

Walk[\%]

(a)

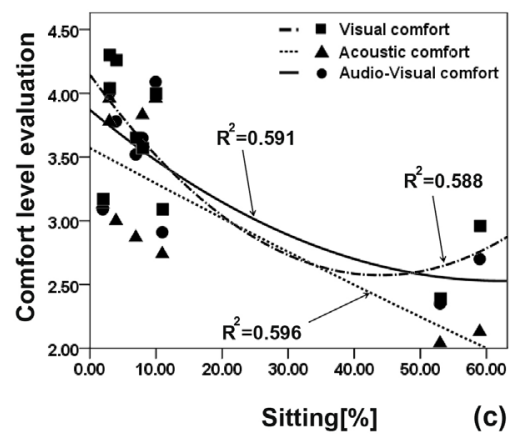

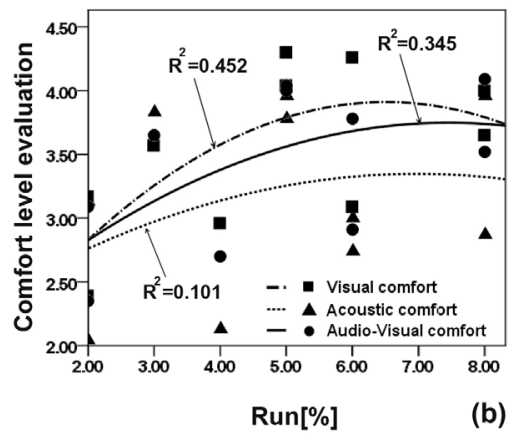

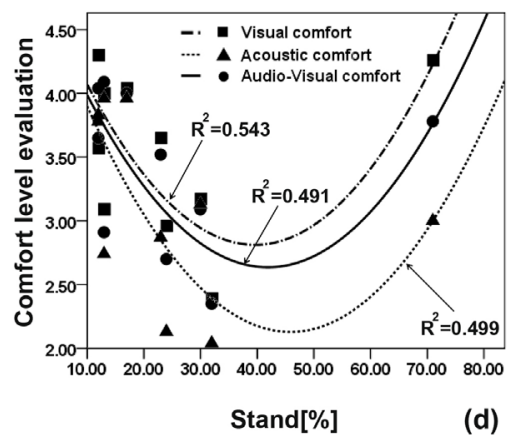

Figure 7. The relationship between each behaviour pattern and comfort evaluation: (a) walking; (b) running; (c) sitting, and (d) standing. The comfort level is graded as per the following linear scale: 1 - very uncomfortable; 2 - uncomfortable; 3 - neither comfortable nor uncomfortable; 4 - comfortable, and 5 - very comfortable

soundscape should have no effect on visual comfort in this study. As such, only acoustic and audio-visual comfort were discussed in this section. From Table 3, significant negative correlations were observed between SPL and acoustic comfort $\left(r=-0.778^{\star *}, p<0.01\right)$, and between SPL and audio-visual comfort $\left(r=-0.782^{\star *}, p<0.01\right)$. These results were consistent with previous studies, indicating that pleasantness can increase with a reduction in the environmental noise level (Echevarria Sanchez et al., 2017; Liu \& Kang, 2018).

Figure 8 shows the relationships between the measured SPL values and the comfort level evaluation, with corresponding quadratic regressions and correlation coefficients $R^{2}$. In Figure 8, each symbol represents the average of the comfort level evaluation for a specific value of SPL. With an increase in SPL, both acoustic and audio-visual comfort levels decrease, with $R^{2}$ value of 0.398 and 0.457 for acoustic and audio-visual comfort, respectively. These results suggest that SPL variation accounts for 39.8\% and $45.7 \%$ of variability in the subjective acoustic and audiovisual comfort levels, respectively. To inspire positive attitudes in participants in terms of audio-visual comfort, SPL should be limited to approximately $82 \mathrm{~dB}$, according to Figure 8. Low audio-visual comfort levels appear on the sites that either include annoying noise from cicadas at the base of a mountain (Site 10) or loudspeakers broadcasting music and notification about people lost and found on scene spots (Site 3, 4 and 5), as seen in Figure 8 and Table 1.

The critical point increased $24 \mathrm{~dB}$ in the mountainous landscape as opposed to the urban street areas, where
SPL should be limited to approximately $58 \mathrm{~dB}$ to inspire positive attitudes in terms of audio-visual comfort (Liu \& Kang, 2018). One possible explanation is that respondents' tolerance of natural sounds (singing birds, gentle wind and streams) could be high relative to the traffic noise on urban streets (Hong \& Jeon, 2013, 2014; Santangelo et al., 2010; Talsma et al., 2010). Indeed, previous studies have shown that natural sounds, especially birdsongs, can promote a feeling of safety and security, which are beneficial to human in recovering from stressful emotions (Bratman et al., 2012; Ratcliffe et al., 2013).

Table 3 indicates that there were no significant correlations between sharpness and acoustic comfort, between

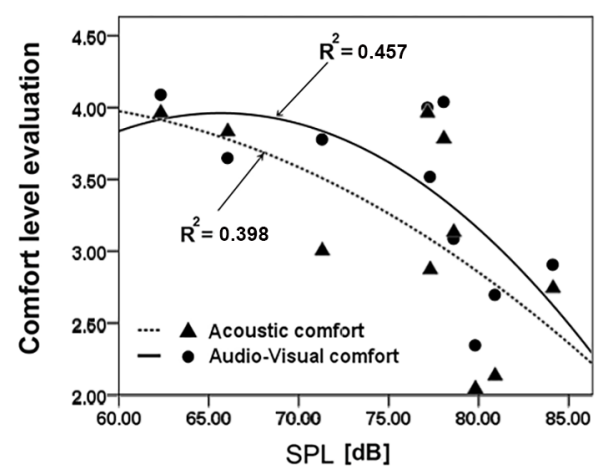

Figure 8. The relationship between SPL and comfort evaluation. The comfort level is graded as per the following linear scale:

1 - very uncomfortable; 2 - uncomfortable; 3 - neither comfortable nor uncomfortable; 4 - comfortable, and 5 - very comfortable 

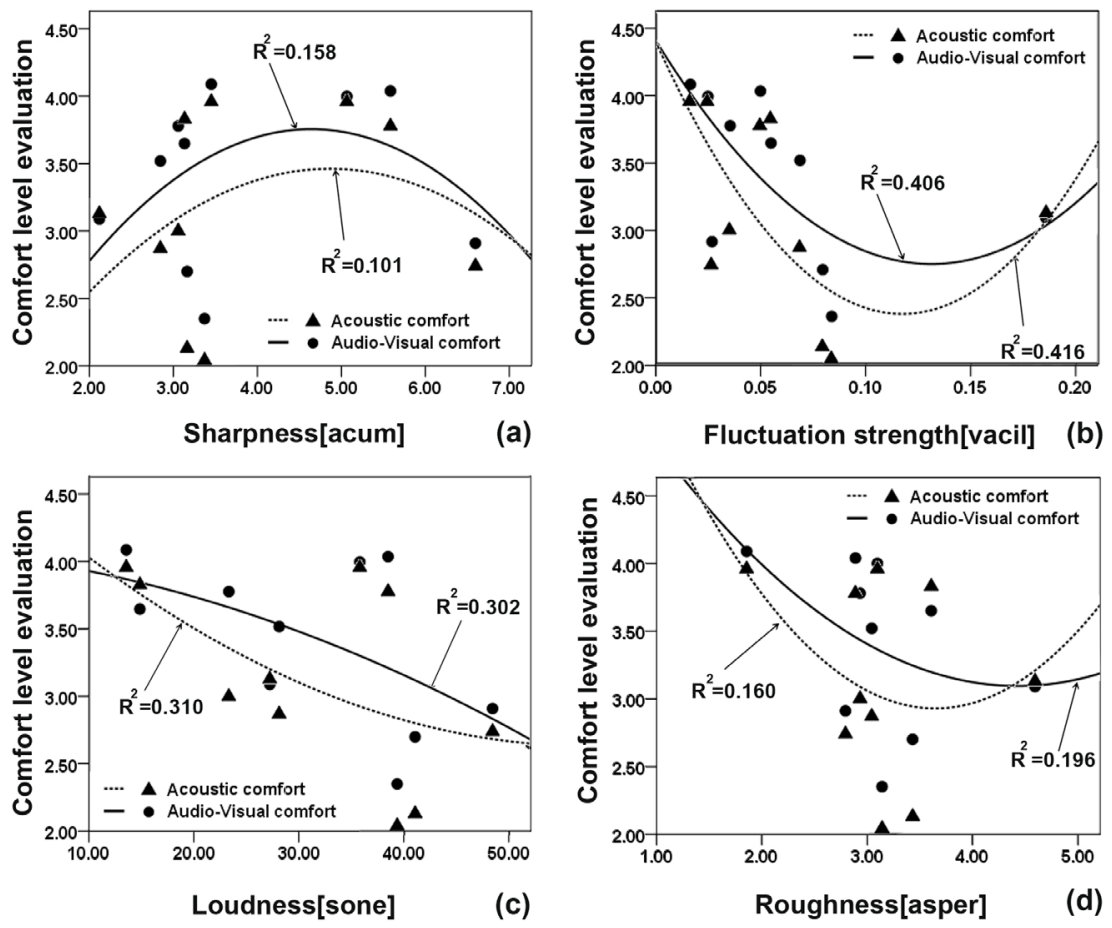

Figure 9. The relationship between each psychoacoustic variable and comfort evaluation: (a) sharpness; (b) fluctuation strength;

(c) loudness, and (d) roughness. The comfort level is graded as per the following linear scale: 1 - very uncomfortable; 2 uncomfortable; 3 - neither comfortable nor uncomfortable; 4 - comfortable, and 5 - very comfortable

sharpness and audio-visual comfort, between roughness and acoustic comfort, and between roughness and audiovisual comfort $(p>0.05)$. Moreover, the values of determination $R^{2}$ from quadratic regression are small (Figure 9a and $\left.\mathrm{d}, R^{2}<0.20\right)$. These results demonstrate that the variation of sharpness or roughness accounts for a limited portion of the variability in both the acoustic and audio-visual comfort levels.

As seen in Table 3, there was a significant negative correlation between fluctuation and audio-visual comfort $\left(r=-0.709^{*}, p<0.05\right)$, but no significant correlation was observed between fluctuation and acoustic comfort $(r=-0.596, p>0.05)$. In addition, values of determination $R^{2}$ from quadratic regression are 0.416 and 0.406 for acoustic comfort and audio-visual comfort, respectively (Figure 9b). These results suggest that fluctuation variation accounts for $41.6 \%$ and $40.6 \%$ of variability in the subjective acoustic and audio-visual comfort levels, respectively. High audio-visual comfort levels are observed when fluctuation is within 0.08 vacil.

From the data shown in Table 3 , it is observed that loudness is negatively correlated with both acoustic comfort $\left(r=-0.681^{*}, p<0.05\right)$ and audio-visual comfort $\left(r=-0.624^{*}, p<0.05\right)$. This trend is consistent with that of urban areas, where a decrease of $6 \%$ in the degree of satisfaction is associated with an increase of every 1 sone (Brambilla et al., 2013). In addition, the values of determination $R^{2}$ from quadratic regression are 0.310 and 0.302 for acoustic comfort and audio-visual comfort, respectively, suggesting that fluctuation variation accounts for
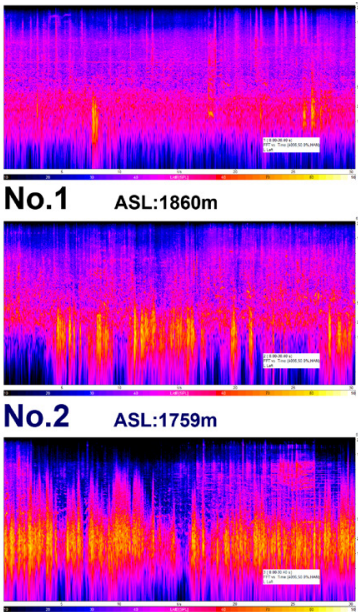

No.3 ASL:1714m

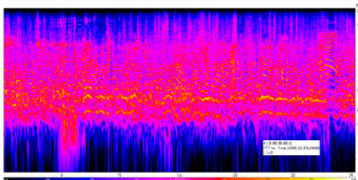

No.4 ASL:1864m

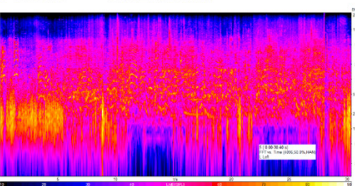

No.5 ASL:1669m
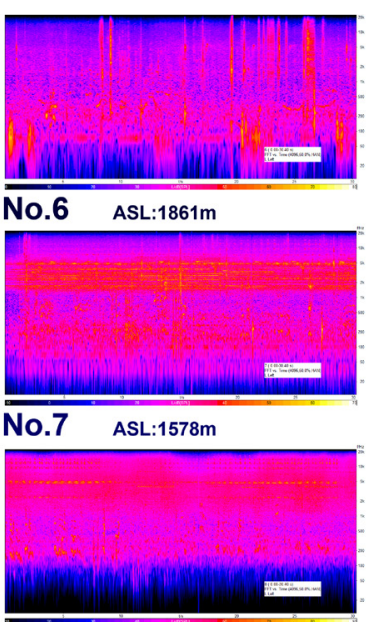

No.8 ASL:1273m

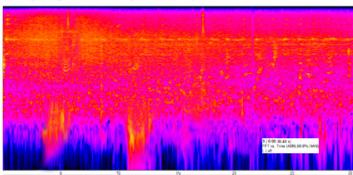

No.9 ASL:1206m

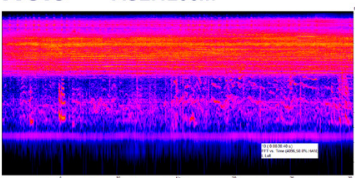

No.10 ASL:815m
Figure 10. The acoustic spectrum for each selected scenic site 
$31.0 \%$ and $30.2 \%$ of variability in the subjective acoustic and audio-visual comfort levels, respectively (Figure 9c). High values of audio-visual levels can be obtained when the loudness is less than 46 sone.

\subsection{Effect of sound sources}

Natural sounds can have an important effect on subjective comfort levels. Figure 4 shows that Nos. 7, 8 and 9 are the three scenic sites showing the highest audio-visual evaluation. On one hand, the high comfort can be related to their natural landscape. As seen in Figure 2 and Table 1, the three sites have large green areas, and they show low population density $\left(\leq 0.05\right.$ person $\left./ \mathrm{m}^{2}\right)$. Some findings have shown that subjective visual quality is positively correlated with factors including the degree of wilderness and the percentage of plant cover (Arriaza et al., 2004). On the other hand, activities and behaviours of the crowd can have an influence on wildlife: the sharp sounds from birds and insects are reduced with increasing population density. This hypothesis is supported by sound spectrograms derived from recordings randomly selected on each site (Figure 10). Although the noise is not constant in these spectrograms, typical characteristics of sounds are revealed from 30-second recordings on each site (Yang \& Kang, 2016). The singing frequency of birds is mainly distributed at a high frequency between $20 \mathrm{~Hz}$ and $9 \mathrm{kHz}$ (Rheindt, 2003). Figure 10 shows that the band corresponding to singing birds is enhanced, and the distribution of the frequency bands is relatively uniform from $20 \mathrm{~Hz}$ to $9 \mathrm{kHz}$ on Site Nos. 7, 8 and 9. Moreover, sounds of the stream gurgling down can be heard in the background on these sites. This type of sound is similar to the ensemble music of various instruments, so it can be beneficial, causing people to feel pleasant. Therefore, these three sites show high acoustic comfort at all scenic sites (Figure 4). In contrast, the acoustic comfort level is relatively low at Site No. 10. This could be caused by the strong, annoying noise from the cicadas, whose population is very large in the park under the shade of the green trees $(2-5 \mathrm{kHz})$. Although taxonomic groups including bats and invertebrates are commonly seen in the park, their ultrasonic spectrum $(>20 \mathrm{kHz})$ is not taken into consideration since these sounds cannot be heard by humans (Fairbrass et al., 2017).

All these results suggest that, in addition to SPL, the composition of sound sources can have strong influence on subjective comfort levels, which is consistent with previous studies (Preis et al., 2015; Ren \& Kang, 2015). When SPL is $<82 \mathrm{~dB}$, our study shows that sounds from singing birds, gentle wind and streams are associated with a positive attitude from respondents, which can be due to the stress recovery and attention restoration effect of the natural sounds (Abbott et al., 2016). However, loud noise from insects and loudspeakers can counteract the positive effect of natural sounds, giving rise to low audio-visual comfort levels when SPL is $>82 \mathrm{~dB}$.

\section{Conclusions}

This article explores subjective comfort evaluations in mountainous landscapes:

(1) Both visual and audio-visual comfort levels are significantly negatively correlated with the population density, and positive audio-visual evaluation is obtained when population density is smaller than 0.82 person $/ \mathrm{m}^{2}$. In addition, the activity of visitors can affect the soundscape: a significant negative correlation is observed between sharpness and density, while positive correlations exist between fluctuation and density and between roughness and density.

(2) In terms of human behaviour patterns, the ratio of dynamic states is positively correlated with all three indicators (the visual, acoustic, and audio-visual comfort levels).

(3) With regard to psychoacoustic parameters, significant negative correlations were observed between SPL and acoustic comfort and between SPL and audio-visual comfort, which is consistent with evaluations in urban areas. An increase in the critical point of SPL in mountainous areas suggests that respondents' tolerance of natural sounds (singing birds, gentle wind and streams) could be high relative to that of traffic noise on urban streets.

(4) Sound sources can have an effect on subjective comfort evaluation. Sites showing both high acoustic and audio-visual comfort levels are associated with their enhanced levels of birdsong and sounds of streams gurgling heard in the background, and these sites exhibit relatively low population density and large green areas.

Overall, respondents would be more comfortable in terms of the audio-visual level in a mountainous area with a relatively high percentage of dynamic state and low fluctuation, loudness, SPL, and population density. It is believed that these findings can be beneficial for gaining high levels of audio-visual comfort by reasonably predicting and controlling tourist density and behaviours in mountainous environments.

\section{Acknowledgements}

This work was supported by the National Natural Science Foundation of China (51608147, 51878210, 51678180, and 51878202).

\section{Author contributions}

The manuscript was written through contributions of all authors.

\section{Disclosure statement}

The authors declare no competing financial interest.

\section{References}

Abbott, L. C., Taff, D., Newman, P., Benfield, J. A., \& Mowen, A. J. (2016). The influence of natural sounds on attention 
restoration. Journal of Park and Recreation Administration, 34(3). https://doi.org/10.18666/JPRA-2016-V34-I3-6893

Arriaza, M., Cañas-Ortega, J. F., Cañas-Madueño, J. A., \& Ruiz-Aviles, P. (2004). Assessing the visual quality of rural landscapes. Landscape and Urban Planning, 69(1), 115-125. https://doi.org/10.1016/j.landurbplan.2003.10.029

Barroso, F. L., Pinto-Correia, T., Ramos, I. L., Surová, D., \& Menezes, H. (2012). Dealing with landscape fuzziness in user preference studies: Photo-based questionnaires in the Mediterranean context. Landscape and Urban Planning, 104(3), 329-342. https://doi.org/10.1016/j.landurbplan.2011.11.005

Bertucci, F., Parmentier, E., Lecellier, G., Hawkins, A. D., \& Lecchini, D. (2016). Acoustic indices provide information on the status of coral reefs: An example from Moorea Island in the South Pacific. Scientific Reports, 6, 33326.

https://doi.org/10.1038/srep33326

Brambilla, G., Gallo, V., Asdrubali, F., \& D’Alessandro, F. (2013). The perceived quality of soundscape in three urban parks in Rome. The Journal of the Acoustical Society of America, 134(1), 832-839. https://doi.org/10.1121/1.4807811

Bratman, G. N., Hamilton, J. P., \& Daily, G. C. (2012). The impacts of nature experience on human cognitive function and mental health. Annals of the New York Academy of Sciences, 1249(1), 118-136. https://doi.org/10.1111/j.1749-6632.2011.06400.x

Brown, A. L., Kang, J., \& Gjestland, T. (2011). Towards standardization in soundscape preference assessment. Applied Acoustics, 72(6), 387-392.

https://doi.org/10.1016/j.apacoust.2011.01.001

Bulut, Z., \& Yilmaz, H. (2008). Determination of landscape beauties through visual quality assessment method: A case study for Kemaliye (Erzincan/Turkey). Environmental Monitoring and Assessment, 141(1), 121-129. https://doi.org/10.1007/s10661-007-9882-0

De Ruiter, E. P. J. (2005). Reclaiming land from urban traffic noise impact zones, "The great canyon". Paper presented at the Sasbe.

Dupont, L., Ooms, K., Antrop, M., \& Van Eetvelde, V. (2016). Comparing saliency maps and eye-tracking focus maps: The potential use in visual impact assessment based on landscape photographs. Landscape and Urban Planning, 148, 17-26. https://doi.org/10.1016/j.landurbplan.2015.12.007

Dupont, L., Ooms, K., Antrop, M., \& Van Etvelde, V. (2017). Testing the validity of a saliency-based method for visual assessment of constructions in the landscape. Landscape and Urban Planning, 167, 325-338.

https://doi.org/10.1016/j.landurbplan.2017.07.005

Echevarria Sanchez, G. M., Van Renterghem, T., Sun, K., De Coensel, B., \& Botteldooren, D. (2017). Using Virtual Reality for assessing the role of noise in the audio-visual design of an urban public space. Landscape and Urban Planning, 167, 98-107. https://doi.org/10.1016/j.landurbplan.2017.05.018

Fairbrass, A. J., Rennert, P., Williams, C., Titheridge, H., \& Jones, K. E. (2017). Biases of acoustic indices measuring biodiversity in urban areas. Ecological Indicators, 83, 169-177. https://doi.org/10.1016/j.ecolind.2017.07.064

Fastl, H., \& Zwicker, E. (2007). Psychoacoustics: Facts and models; with 53 psychoacoustics demonstrations on CD-ROM [compact disc, audio CD-ROM]. Springer. https://doi.org/10.1007/978-3-540-68888-4

Francis, C. D., Newman, P., Taff, B. D., White, C., Monz, C. A., Levenhagen, M., Petrelli, A. R., Abbott, L. C., Newton, J., Burson, S., Cooper, C. B., Fristrup, K. M., McClure, C. J. W., Mennitt, D., Giamellaro, M., \& Barber, J. R. (2017). Acoustic environments matter: Synergistic benefits to humans and eco- logical communities. Journal of Environmental Management, 203(Part 1), 245-254.

https://doi.org/10.1016/j.jenvman.2017.07.041

Fuller, S., Axel, A. C., Tucker, D., \& Gage, S. H. (2015). Connecting soundscape to landscape: Which acoustic index best describes landscape configuration? Ecological Indicators, 58, 207-215. https://doi.org/10.1016/j.ecolind.2015.05.057

George, D., \& Mallery, P. (2013). IBM SPSS statistics 21 step by step: A simple guide and reference. Pearson.

Haas, G. E., \& Wakefield, T. J. (1998). National parks and the American public: A national public opinion survey on the $\mathrm{Na}$ tional Park System. National Parks and Conservation Association and Colorado State University. Washington DC and Fort Collins, CO.

Hao, Y., Kang, J., \& Krijnders, J. D. (2015). Integrated effects of urban morphology on birdsong loudness and visibility of green areas. Landscape and Urban Planning, 137, 149-162. https://doi.org/10.1016/j.landurbplan.2015.01.006

Hermida Cadena, L. F., Lobo Soares, A. C., Pavón, I., \& Bento Coelho, L. (2017). Assessing soundscape: Comparison between in situ and laboratory methodologies. Noise Mapping, 4(1), 57-66. https://doi.org/10.1515/noise-2017-0004

Hong, J. Y., \& Jeon, J. Y. (2013). Designing sound and visual components for enhancement of urban soundscapes. The Journal of the Acoustical Society of America, 134(3), 20262036. https://doi.org/10.1121/1.4817924

Hong, J. Y., \& Jeon, J. Y. (2014). The effects of audio-visual factors on perceptions of environmental noise barrier performance. Landscape and Urban Planning, 125, 28-37. https://doi.org/10.1016/j.landurbplan.2014.02.001

Joynt, J. L. R., \& Kang, J. (2010). The influence of preconceptions on perceived sound reduction by environmental noise barriers. Science of The Total Environment, 408(20), 4368-4375. https://doi.org/10.1016/j.scitotenv.2010.04.020

Kang, J. (2000). Sound propagation in street canyons: Comparison between diffusely and geometrically reflecting boundaries. The Journal of the Acoustical Society of America, 107(3), 1394-1404. https://doi.org/10.1121/1.428580

Kang, J. (2007). Urban sound environment. Routledge. https://doi.org/10.1201/9781482265613

Liu, F., \& Kang, J. (2018). Relationship between street scale and subjective assessment of audio-visual environment comfort based on 3D virtual reality and dual-channel acoustic tests. Building and Environment, 129, 35-45. https://doi.org/10.1016/j.buildenv.2017.11.040

López-Martínez, F. (2017). Visual landscape preferences in Mediterranean areas and their socio-demographic influences. Ecological Engineering, 104(Part A), 205-215. https://doi.org/10.1016/j.ecoleng.2017.04.036

Marin, L. D., Newman, P., Manning, R., Vaske, J. J., \& Stack, D. (2011). Motivation and acceptability norms of human-caused sound in Muir Woods National Monument. Leisure Sciences, 33(2), 147-161.

https://doi.org/10.1080/01490400.2011.550224

Meng, Q., Sun, Y., \& Kang, J. (2017). Effect of temporary openair markets on the sound environment and acoustic perception based on the crowd density characteristics. Science of the Total Environment, 601-602, 1488-1495. https://doi.org/10.1016/j.scitotenv.2017.06.017

Motoyama, Y., \& Hanyu, K. (2014). Does public art enrich landscapes? The effect of public art on visual properties and affective appraisals of landscapes. Journal of Environmental Psychology, 40, 14-25. https://doi.org/10.1016/j.jenvp.2014.04.008 
Newman, G., Wiggins, A., Crall, A., Graham, E., Newman, S., \& Crowston, K. (2012). The future of citizen science: Emerging technologies and shifting paradigms. Frontiers in Ecology and the Environment, 10(6), 298-304.

https://doi.org/10.1890/110294

Pilcher, E. J., Newman, P., \& Manning, R. E. (2008). Understanding and managing experiential aspects of soundscapes at Muir Woods National Monument. Environmental Management, 43(3), 425. https://doi.org/10.1007/s00267-008-9224-1

Polat, A. T., \& Akay, A. (2015). Relationships between the visual preferences of urban recreation area users and various landscape design elements. Urban Forestry \& Urban Greening, 14(3), 573-582. https://doi.org/10.1016/j.ufug.2015.05.009

Preis, A., Kociński, J., Hafke-Dys, H., \& Wrzosek, M. (2015). Audio-visual interactions in environment assessment. Science of the Total Environment, 523, 191-200. https://doi.org/10.1016/j.scitotenv.2015.03.128

Ratcliffe, E., Gatersleben, B., \& Sowden, P. T. (2013). Bird sounds and their contributions to perceived attention restoration and stress recovery. Journal of Environmental Psychology, 36, 221228. https://doi.org/10.1016/j.jenvp.2013.08.004

Ren, X., \& Kang, J. (2015). Effects of the visual landscape factors of an ecological waterscape on acoustic comfort. Applied Acoustics, 96, 171-179.

https://doi.org/10.1016/j.apacoust.2015.03.007

Renterghem, T. V., Botteldooren, D., \& Lercher, P. (2007). Comparison of measurements and predictions of sound propagation in a valley-slope configuration in an inhomogeneous atmosphere. The Journal of the Acoustical Society of America, 121(5), 2522-2533. https://doi.org/10.1121/1.2717765

Rheindt, F. E. (2003). The impact of roads on birds: Does song frequency play a role in determining susceptibility to noise pollution? Journal für Ornithologie, 144(3), 295-306. https://doi.org/10.1046/j.1439-0361.2003.03004.x

Rossi, F., Anderini, E., Castellani, B., Nicolini, A., \& Morini, E. (2015). Integrated improvement of occupants' comfort in urban areas during outdoor events. Building and Environment, 93(Part 2), 285-292.

https://doi.org/10.1016/j.buildenv.2015.07.018

Santangelo, V., Fagioli, S., \& Macaluso, E. (2010). The costs of monitoring simultaneously two sensory modalities decrease when dividing attention in space. NeuroImage, 49(3), 27172727. https://doi.org/10.1016/j.neuroimage.2009.10.061

Schormans, A. L., Typlt, M., \& Allman, B. L. (2017). Crossmodal plasticity in auditory, visual and multisensory cortical areas following noise-induced hearing loss in adulthood. Hearing Research, 343, 92-107.

https://doi.org/10.1016/j.heares.2016.06.017
Sever, I., \& Verbič, M. (2018). Providing information to respondents in complex choice studies: A survey on recreational trail preferences in an urban nature park. Landscape and Urban Planning, 169(Suppl C), 160-177. https://doi.org/10.1016/j.landurbplan.2017.09.003

Talsma, D., Senkowski, D., Soto-Faraco, S., \& Woldorff, M. G. (2010). The multifaceted interplay between attention and multisensory integration. Trends in Cognitive Sciences, 14(9), 400-410. https://doi.org/10.1016/j.tics.2010.06.008

UNESCO. (2019). Mount Huangshan - UNESCO World Heritage Center. http://whc.unesco.org/pg.cfm?cid=31\&id_site $=547$

Watkins, S., Shams, L., Josephs, O., \& Rees, G. (2007). Activity in human V1 follows multisensory perception. NeuroImage, $37(2), 572-578$.

https://doi.org/10.1016/j.neuroimage.2007.05.027

Watson, J. E. M., Dudley, N., Segan, D. B., \& Hockings, M. (2014). The performance and potential of protected areas. Nature, 515, 67-73. https://doi.org/10.1038/nature13947

Xie, H., Li, H., Liu, C., Li, M., \& Zou, J. (2016). Noise exposure of residential areas along LRT lines in a mountainous city. Science of the Total Environment, 568, 1283-1294. https://doi.org/10.1016/j.scitotenv.2016.03.097

Yan, B., Chen, S. B., \& Deng, S. Y. (2013). An exploration into green land system and unexpected disaster prevention in mountain city: A case study of the Shapingba Downtown in Chongqing. Applied Mechanics and Materials, 253-255, 151-156.

https://doi.org/10.4028/www.scientific.net/AMM.253-255.151

Yang, M., \& Kang, J. (2016). Pitch features of environmental sounds. Journal of Sound and Vibration, 374, 312-328. https://doi.org/10.1016/j.jsv.2016.03.040

Yang, W., \& Kang, J. (2005). Soundscape and sound preferences in urban squares: A case study in Sheffield. Journal of Urban Design, 10(1), 61-80.

https://doi.org/10.1080/13574800500062395

Yu, L., \& Kang, J. (2009). Modeling subjective evaluation of soundscape quality in urban open spaces: An artificial neural network approach. The Journal of the Acoustical Society of America, 126(3), 1163-1174. https://doi.org/10.1121/1.3183377

Yu, T., Behm, H., Bill, R., \& Kang, J. (2017). Audio-visual perception of new wind parks. Landscape and Urban Planning, 165, 1-10. https://doi.org/10.1016/j.landurbplan.2017.04.012

Zhang, M., \& Kang, J. (2007). Towards the evaluation, description, and creation of soundscapes in urban open spaces. Environment and Planning B: Planning and Design, 34(1), 68-86. https://doi.org/10.1068/b31162 